\title{
Modeling PV installations under partial shading conditions
}

\author{
Afef Bennani-Ben Abdelghani ${ }^{1,2}$ (D) $\cdot$ Houda Ben Attia Sethom ${ }^{2,3}$
}

Received: 11 November 2019 / Accepted: 9 March 2020 / Published online: 12 March 2020

(c) Springer Nature Switzerland AG 2020

\begin{abstract}
This paper deals with the development of a photovoltaic (PV) array model under partial shading conditions. Based on the one diode equivalent circuit of a PV cell, and mathematical developments proposed in literature, the authors propose a simple and accurate model of PV arrays under partial shading conditions. First, the equations to calculate the needed I-V curve parameters are presented. Then, the paper synthesizes a simple implementation of these equations on MATLAB software. In order to validate the author's propositions, experimental results are carried out on two parallel connected 180 W PV modules. Each module has 72 mono-crystalline cells, connected in series and organized in 3 cell strings. Each cell string has 24 cells and is protected by one bypass diode. The simulation and experimental results aim to prove the performances of the proposed modeling methodology of the PV module and/or array when partially shaded.
\end{abstract}

Keywords PV array · Serial-parallel configuration · Partial shading · Bypass diode

\section{Introduction}

Photovoltaic systems are interesting renewable energy sources but their performances highly depend on the external conditions, especially the climate environment and electric utility quality for grid connected applications.

Many research studies have focused on the impact of the grid faults on photovoltaic installation performances $[1,2]$ and how the environment conditions (dust, temperature, irradiance, soiling) affect the produced energy [3]. High performance MPPT (Maximum Power Point Tracking) algorithms have been proposed [4-8] in order to solve the stated issues. Furthermore, one can notice that the photovoltaic system span in low medium and high voltage, distribution and transport grids have emerged non negligible effects on the power quality of the electric utility [9-11]. In the framework of the PEER (Partnerships For Enhanced Engagement In Research) Project named Impact of rooftop PV system integration on Tunisian electrical distribution network' [12], the members of the stated project are collaborating with the authors of this paper to propose a PV emulator capable of reproducing a PV system behavior under healthy and partially shading conditions. The work presented in this paper is the first step of one of this PEER Project Work Packages since a PV emulator needs the equivalent PV system I-V curve. Besides, the determination of the I-V characteristic of a $\mathrm{PV}$ array is difficult since an accurate prediction of the climate and environmental conditions is intricate and the behavior of photovoltaic cells makes it nonlinear. This issue becomes more complicated when the entire PV array receives non-uniform irradiance, i.e. under partial shading condition.

All manufacturer's data sheets cannot provide all the information required to model the PV array in various operation conditions. Therefore, a method to obtain the required parameters from the available technical data is needed. Although several researchers have studied the PV

$\triangle$ Afef Bennani-Ben Abdelghani, afef.bennani@gmail.com; Houda Ben Attia Sethom, houda.benattia@gmail.com | ${ }^{1}$ Université de Carthage, Institut National des Sciences Appliquées et Technologie, INSAT, 1080 Tunis, Tunisia. ${ }^{2}$ Université Tunis EI Manar, Ecole Nationale d'Ingénieurs de Tunis, LR11ES15, Laboratoire des Systèmes Electriques, 1002 Tunis, Tunisia. ${ }^{3}$ Université de Carthage, Ecole Nationale d'Ingénieurs de Carthage, ENICarthage, 2035 Tunis, Tunisia. 
array behavior under partial shading conditions [13-15], many of them described only the arrays formed by modules in series, as in $[16,17]$. In [18], the authors studied the PV arrays formed by serial-parallel modules under partial shade condition but they took into account only one level of shade ( $0 \%$ insulation).

To reduce calculation tasks, and maintain the accuracy of PV array's output reproduction using a small set of technical data provided by the manufacturer, this paper proposes a simple method to analytically find out the parameter values of a PV array model. Also, the paper introduces an extension of the method presented in [16] in order to consider series/parallel configurations to model PV arrays partially shaded with serial-parallel module topologies. The model presented in this paper is simple and relevant to any level of shade.

This paper is organized as follows: In the second section, the mathematic model of the one-diode equivalent circuit of a photovoltaic cell is detailed. Based on this model, the authors propose, in section III, a simple method to calculate the one-diode parameters under a given temperature and radiation values couple. The radiation value can change from one cell to another providing a model suitable for partial shading conditions. In Sect. 4, the experimental test is described and the obtained results are discussed in Sect. 5 proving the author propositions performances and giving the next steps to improve them.

\section{Mathematical model for a photovoltaic cell}

\subsection{Modeling the photovoltaic cell}

In the literature, there are several PV cell models (ideal model, one-diode and two-diode model...) [4]. The single-diode model is one of the most commonly used. The corresponding circuit equivalent to a solar cell is shown in Fig. 1, it has four components: a current source, one diode and two resistors to represent the losses: one in series $R s$ and one in parallel Rsh.

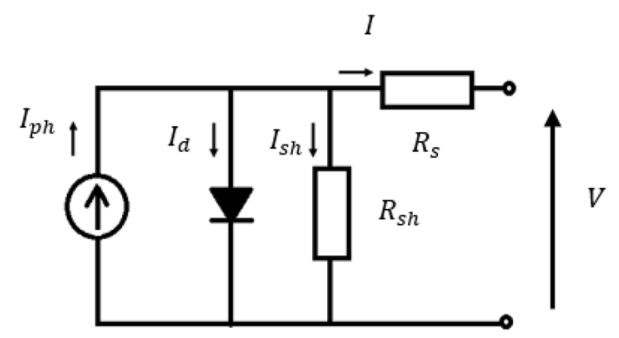

The output voltage $\mathrm{V}$ and the load current I are related as:

$I=I_{p h}-I_{d}-I_{s h}=I_{p h}-I_{s}\left[e^{\frac{v+R_{s} I}{a}}-1\right]-\frac{V+R_{s} I}{R_{s h}}$

where: $a=\frac{A K T}{q} ; l_{p h}$ : Photocurrent $(A) ; l_{s}$ : saturation current $(\mathrm{A}) ; R_{s}$ : series resistance $(\Omega) ; R_{s h}$ : shunt résistance $(\Omega) ;$ a: modified ideal factor $(\mathrm{V})$; $\mathrm{A}$ : diode ideal factor; $\mathrm{T}$ : cell temperature $(\mathrm{K})$; q: electron charge $\left(1602 \times 10^{-19} \mathrm{C}\right)$; k: Boltzmann constant $\left(1.38 \times 10^{-23} \mathrm{~J} / \mathrm{K}\right)$.

\subsection{Parameter calculation}

The five parameters $\left(I_{p h}, l_{s}, R_{s}, R_{s h}, \mathrm{~A}\right)$ must be determined to construct the I-V curve. They are obtained using Eqs. (2)-(6) and they depend on irradiance, temperature, manufacturer data and reference parameters [16, 19-21].

$I_{p h}=\frac{G}{G_{\text {ref }}} \cdot\left[I_{\text {ph_ref }}+\mu_{\text {isc }} \cdot\left(T-T_{\text {ref }}\right)\right]$

$I_{S}=I_{s_{-} \text {ref }} \cdot\left(\frac{T}{T_{\text {ref }}}\right)^{3} \cdot e^{\left[\left(\frac{q . F g}{A . K}\right) \cdot\left(\frac{1}{T_{\text {ref }}}-\frac{1}{T}\right)\right]}$

$R_{s}=\frac{G_{\text {ref }}}{G} \cdot R_{S_{-} r e f}$

$R_{\text {sh }}=\frac{G_{\text {ref }}}{G} \cdot R_{\text {Sh_ref }}$

$A=A_{\text {ref }} \cdot \frac{T}{T_{\text {ref }}}$

In these equations, the following five reference parameters are required: $I_{p h_{\text {ref }} I_{S_{\text {ref }}}} A_{\text {ref }}, R_{S_{\text {ref }}}$ et $R_{S h_{\text {ref }}}$ which are determined under standard test conditions. It is important to use the Eq. (1) and the available manufacturer data: the open circuit voltage $V_{c o}$, the short circuit current, the voltage, $V_{M P P,}$ and the current, $I_{M P P_{1}}$ at the Maximal Power Point (MPP). Procedures for determining the five parameters are given herewith:

- For short circuit current: $(I=I c c, V=0)$, the diode current can be negleted (I_(ph) $\left.)\rangle I_{-}(\mathrm{s})\right)$ and $\frac{R_{s_{\text {ref }} \cdot \cdot / c c}}{R_{s_{\text {href }}}} \ll 1$ leading to:

$I_{p h_{\text {ref }}}=I c c$

- For open circuit voltage: $(\mathrm{I}=0, \mathrm{~V}=\mathrm{V} c \mathrm{O})$ :

Fig. 1 One diode equivalent circuit of a PV cell 


$$
\begin{aligned}
& 0=I_{p h_{\text {ref }}}-\frac{V c O}{R_{S h_{\text {ref }}}}-I_{S_{\text {ref }}} \cdot\left[e^{\frac{V_{C O}}{a}}-1\right] \\
& I_{S_{\text {ref }}}=\frac{I_{p h_{\text {ref }}}-\frac{V c o}{R_{S h_{\text {ref }}}}}{e^{\frac{V C o}{a}}-1}
\end{aligned}
$$

- At the maximum power point: $\left(I=I_{M P P,} V=V_{M P P}\right)$

$I_{M P P}=I_{p h_{\text {ref }}}-\frac{V_{M P P}+R_{S_{\text {ref }}} \cdot I_{M P P}}{R_{\text {sh }_{\text {ref }}}}-I_{S_{\text {ref }}}\left[e^{\frac{V_{M P P}+R_{\text {ref }} \cdot I_{M P P}}{a}}-1\right]$

Since the value of $R_{s_{\text {ref }}}$ is low, the limited developments given by (11) and (12) are possible.

$e^{R_{\text {sef }}} \approx 1+R_{s_{\text {ref }}}$

$\left(1+R_{s_{\text {ref }}}\right)^{\frac{I_{M P P}}{a}} \approx 1+R_{s_{\text {ref }}} \cdot \frac{I_{M P P}}{a}$

In addition, considering (12), we can deduce (13)

$$
\begin{aligned}
& e^{\frac{V_{M P P}+R_{S_{\text {ref }}} \cdot I_{M P P}}{a}}=e^{\frac{V_{M P P}}{a}} \cdot e^{\frac{R_{\text {ref }} \cdot I_{M P P}}{a}}=e^{\frac{V_{M P P}}{a}} \cdot\left[e^{R_{\text {sef }}}\right] \cdot \frac{I_{M P P}}{a} \\
& R_{S_{\text {ref }}}=\frac{I_{\text {ph }}-I_{\text {ref }}-\frac{V_{M P P}}{R S h_{\text {ref }}}+I_{S_{\text {ref }}}\left(1-e^{\frac{V_{M P P}}{a}}\right)}{I_{M P P} \cdot\left(\frac{I_{\text {ref }}}{a} e^{\frac{V_{M P P}}{a}}+\frac{1}{R s h_{\text {ref }}}\right)}
\end{aligned}
$$

- The slope of the I-V curve at the short circuit point given by (14).

$$
\frac{d l c c}{d V}=\frac{-1}{R s h \_r e f}
$$

Calculating the slope between the short circuit point and the maximum power point gives the expression of shunt resistance:

$R s h_{\text {ref }}=-\frac{0-V m p}{I c c-I m p}$

- The diode ideality factor $A_{\text {ref }}$ takes a value of the interval $\mathrm{I}=[1,2]$. The choice based on empirical analysis $(=2$ for crystaline, $<2$ for amorphous)

\section{Modeling a photovoltaic array under partial shading}

\subsection{Modeling a PV array under partial shading conditions}

Several cells associated in series and protected by bypass diodes form a PV module. In order to obtain a higher power, several modules can be connected in series and/ or parallel to construct a PV array. Figure 2 shows a PV module containing an $\mathrm{n}$ cell string, each one is protected by a bypass diode and contains $\mathrm{m}$ cells in series.

The modeling of the PV module or array consists in determining the I-V characteristic. According to Eq. (1), it is difficult to directly get the relationship values between $\mathrm{I}$ and $\mathrm{V}$. This difficulty is resolved by neglecting the current in shunt resistance. Hence, the simple relationship equation between I and V for a PV cell, module or array can be described as follows:

$V=a \cdot \ln \left(\frac{I_{p h}-I}{I_{s}}+1\right)-R_{s} I$

Consequently, the output voltage of the module having n.m PV cells connected in series, is given by (17)

$V m=n * m * V=n * m *\left(a \cdot \ln \left(\frac{l_{p h}-I}{I_{s}}+1-R_{s} I\right)\right)$

To determine the characteristic I-V of a PV array, it is necessary to determine at first the characteristic I-V of the PV module under partial shading conditions. The following development are based on the analysis of Y. Cao et al. [16], considered as a pioneer in modeling the PV modules.

Assume that the no 1_1 cell in the no 1 cell string is shaded, which is protected by a bypass diode (Fig. 3 ). The photocurrent of the no $1 \_1$ cell $I_{p h_{1-1}}$ which is proportional to solar irradiance, will be less than that of the other cells in the no 1 cell string $I_{p h_{1-i(i=2 \rightarrow m)}}$.

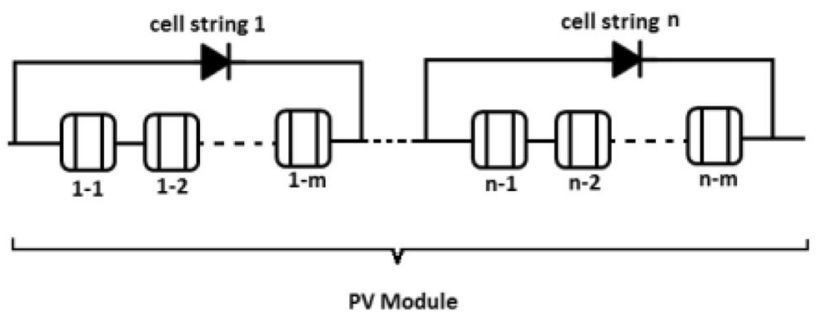

Fig. 2 PV module with $\mathrm{n}$ bypass diodes 


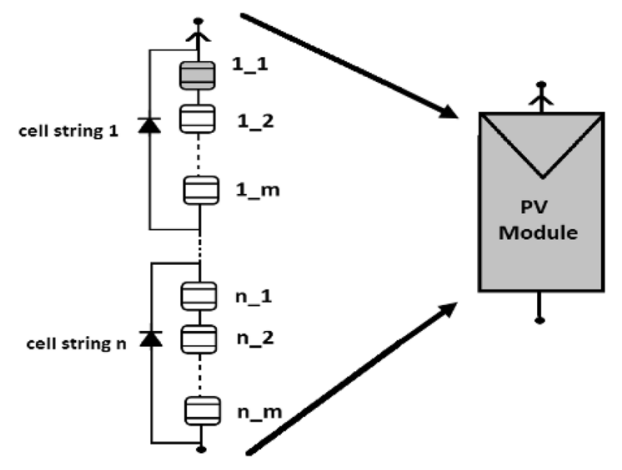

Fig. 3 PV module partially shaded

The PV cell has two operating modes [22]:

- In the first case, $0<I<I_{p h, 1-1}$, the current conducted through the module is smaller than the photocurrent of the $n^{\circ} 1 \_1$ cell. The shaded cell produces power normally and the state of the bypass diode is non-conducting.

So that, the relationship equation between I and $\mathrm{V}$ ${ }_{1-1}$ for a shaded PV cell $\mathrm{n}^{\circ}{ }_{-}{ }_{1}$ is described as follows:

$V_{1 \_1}=a_{1-1} \cdot \ln \left(\frac{I_{p h, 1 \_1}-I}{I_{s, 1 \_1}}+1\right)$

Thus the voltage of the no. 1 cell string can be presented as per the following:

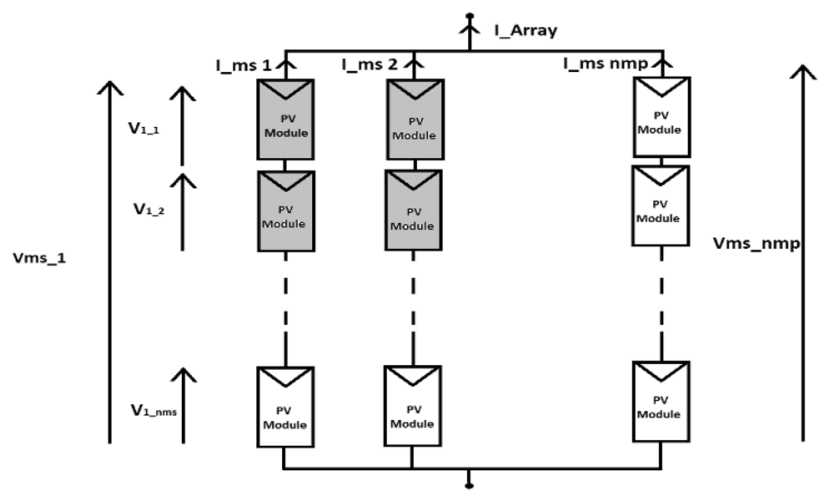

Fig. 4 PV array partially shaded

The relationship between / and $V_{1}$ for a shaded PV module, for different operating modes of a PV cell, is summarized in (21). The characteristics of a PV array get more complicated under a partial shading condition and the output voltage equation of PV array shown in Eq. (21) is not suitable for hybrid configuration of cells. A model of a partially shaded PV array having different configurations (series and/or parallel) of PV modules is proposed in the following.

Considering the partial shading condition, as shown in Fig. 4, a photovoltaic array is formed by $n m p$ series strings of PV modules in parallel; each module string formed by $n m s$ PV modules in series. After determining

$V_{1}=V_{1 \_1}+\sum_{i=2}^{m} V_{1 \_i}==a_{1-1} \cdot \ln \left(\frac{I_{p h, 1_{\_} 1}-I}{I_{s, 1 \_1}}+1\right)-R_{s, 1_{-} 1} I+(m-1) \cdot\left(a \cdot \ln \left(\frac{I_{p h}-I}{I_{s}}+1-R_{s} I\right)\right)$

- In the second case, $I_{p h, 1-1}<I<I_{p h, 1-i}$, the current conducted through the module is larger than the photocurrent of the $n^{\circ} 1 \_1$ cell. The shaded cell is reverse biased and its voltage becomes negative. The state of the bypass diode depends on the threshold value $V d b$ (it is equal to $0.7 \mathrm{~V}$ in silicon case) and the value of the whole cell string.

Thus, the voltage of the $n^{0} 1 \_1$ cell can be written as in (20):

$V_{1 \_1}=-\left(I-I_{p h, 1 \_1}\right) R_{s h, 1 \_1}-R_{s, 1 \_1} I$

Furthermore, the voltage of the $\mathrm{n}^{\circ} 1$ cell string protected by the $n^{\circ} 1$ bypass diode is given by (21):

$V_{1}=V_{1 \_1}+\sum_{i=2}^{m} V_{1 \_i}=-\left(I-I_{p h, 1 \_1}\right) \cdot R_{s h, 1 \_1}-R_{s, 1-1} l+\sum_{i=2}^{m} V_{1 \_i}$ the characteristic I-V of a PV module partially shaded, it is possible to generalize this method to obtain the characteristic I-V of a PV module string. The procedure to obtain the characteristic I-V of the whole PV array consists in the segmentation of all the characteristic I-V of module strings according to different voltage values and summing the currents at each of the characteristic of the module string for the same value of voltage. Therefore, all the operating points of the I-V curve of the PV array are known.

The voltage of the module string $n^{\circ} j$ where $j=[1 ; n m p]$ is the sum of the voltages of $n m s$ modules constituting this chain as shown in (22):

$V_{m s-j}=\sum_{i=1}^{n m s} V_{j_{-} i}$

The current of the array under partial shading conditions is the sum of current products in each module string. For each value $v$ of the voltage interval, the use of 
the segmentation method is necessary to determine the current of every string of modules connected in series. The current of the PV array is described by (23)

$$
I_{\text {Array }}(v)=\sum_{j=1}^{n m p} I_{m s j}(v) .
$$

\subsection{Implementation of the proposed method to model a PV array under partial shading conditions}

Figure 5 shows the procedure to determine the I-V curve of a PV array under partial shading conditions.

Using the manufacture data of the module $\mathrm{PV}\left(\mathrm{I}_{\mathrm{SC}}, \mathrm{V}_{\mathrm{OC}}\right.$ $\left.I_{M P P}, V_{M P P}\right)$ is necessary to determine the reference parameters $\left(a_{\text {ref }}, l_{\text {ph_ref }}, l_{s_{-} \text {ref }}, R_{\text {sh_ref }}, R_{s_{-} r e f}\right)$ which are primordial to compute the parameters of $\mathrm{PV}$ cells $\left(\mathrm{a}, I_{p h}, I_{s}, R_{s h}\right.$ et $\left.R_{s}\right)$ at

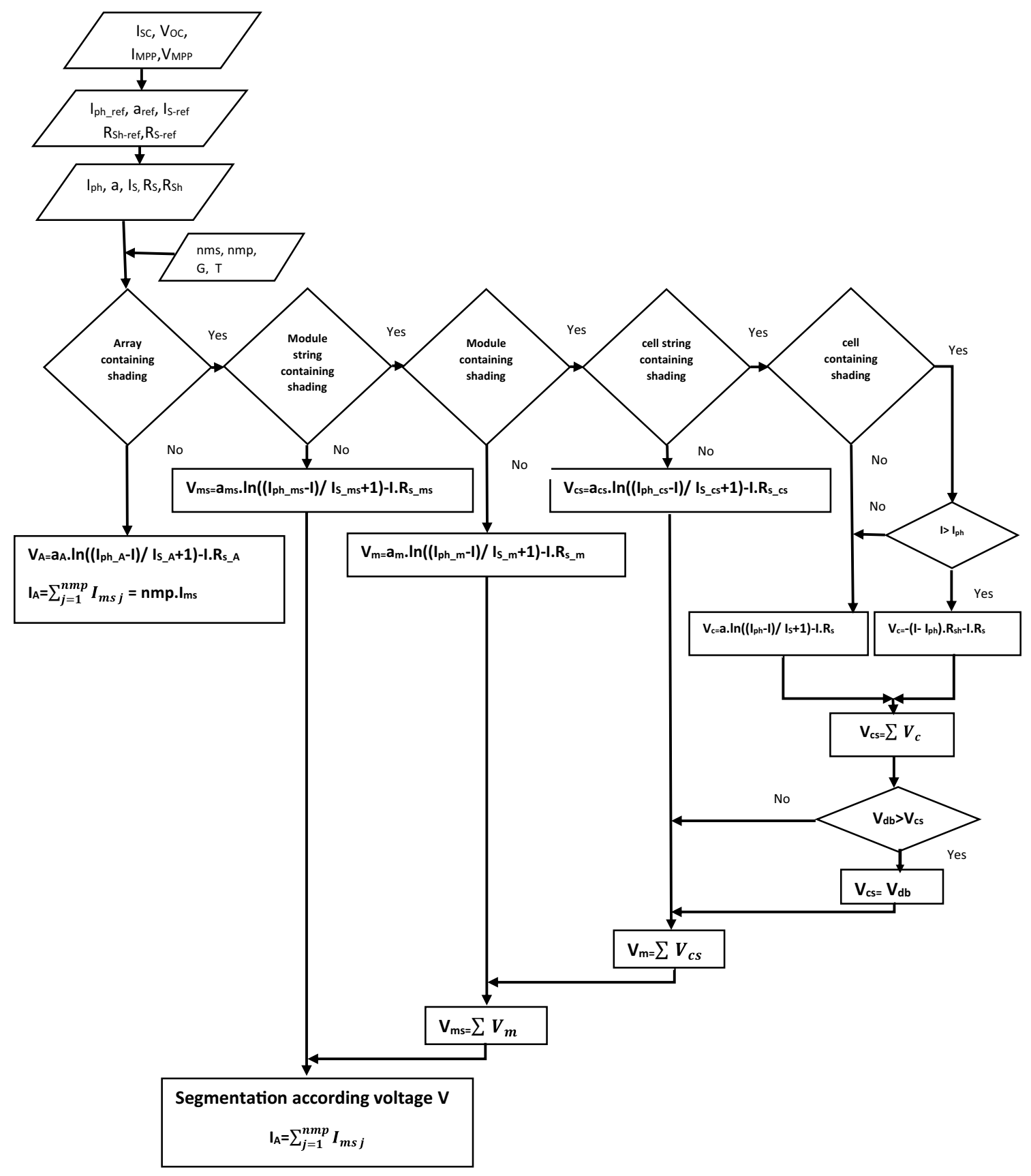

Fig. 5 Diagram of the procedure to determine the characteristic I-V of a PV array under partial shading conditions 
different conditions of temperature and solar irradiance. The following parameters $a_{A^{\prime}} l_{\text {ph_A }} l_{S_{-} A^{\prime}} R_{\text {Sh_A }}, R_{S_{-} A}$ are the PV array parameters on which are based the nmp modules string that has the following five parameters $a_{m s}, l_{\text {ph_ms }}$, $I_{s_{-} m s^{\prime}} R_{\text {sh_ms }}, R_{\text {s_ms }}$.

Each module string consists of nms modules that have the following parameters: $a_{m}, I_{\text {ph_m } m}, I_{s_{-} m}, R_{s_{\_} m}, R_{s_{-} m}$. The parameters $a_{c s^{\prime}} l_{p h \_c s^{\prime}} I_{s_{-} c s^{\prime}}, R_{s h_{-} c s^{\prime}} R_{s_{-} c s}$ are the five parameters of the cell string in the PV module.

\section{Experimental results}

In order to verify and validate experimentally the suggested modeling methodology of the PV array partially shaded, we consider two parallel-connected $180 \mathrm{~W}$ PV modules. Figure 6 describes the configuration of the tested PV array. It can be seen that there are two modules in parallel, each has 72 mono-crystalline cells serially connected, three cell strings and three bypass diodes. Each cell string has 24 cells and is protected by one bypass diode.

The specifications of the PV modules in STC used to obtain the simulation of the characteristic I-V are shown in Table 1.

The I-V characteristic was measured by changing the impedance of seven resistances of $4.7 \Omega$ connected in series in order to obtain several operating points (voltage $V$, current

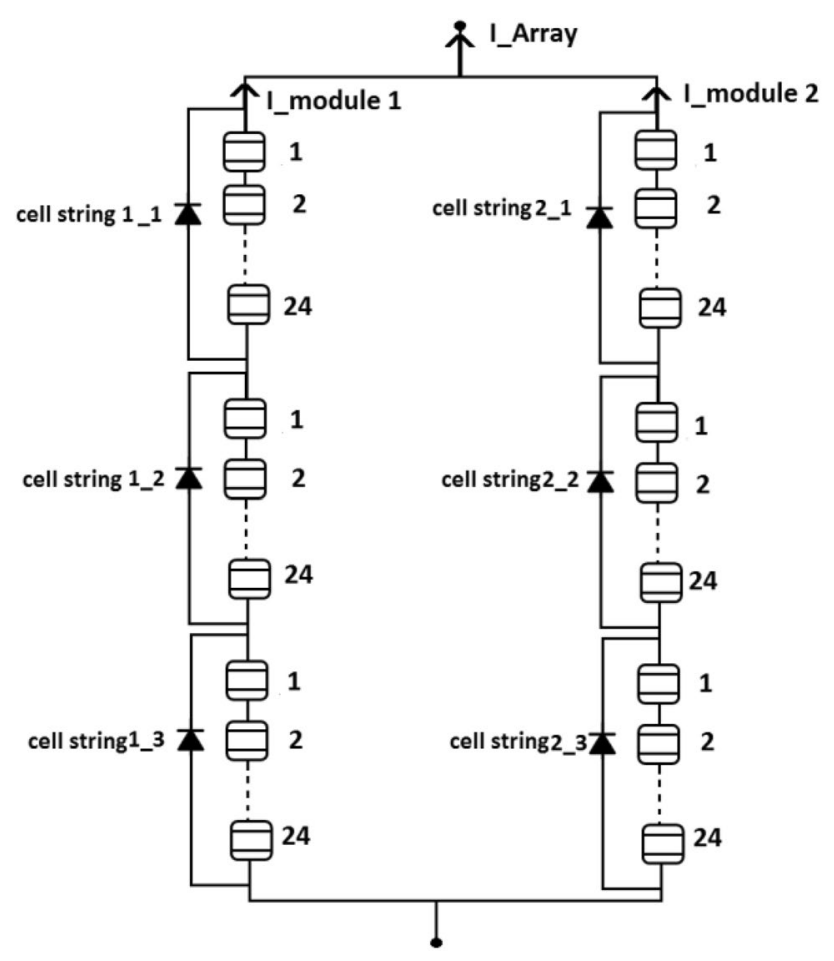

Fig. 6 The configuration of the experimental PV array
Table 1 Manufacturer data of one 180 W PV module

\begin{tabular}{lllll}
\hline$P_{M P P}$ & $I_{M P P}$ & $V_{M P P}$ & $I_{S C}$ & $V_{O C}$ \\
\hline $180 \mathrm{~W}$ & $5 \mathrm{~A}$ & $36 \mathrm{~V}$ & $5.29 \mathrm{~A}$ & $44.8 \mathrm{~A}$ \\
\hline
\end{tabular}

I). The use of digital multi-meter is helpful for more accuracy of measurement. During the measurements, the average irradiance and temperature were $420 \mathrm{~W} / \mathrm{m}^{2}$ and $60^{\circ} \mathrm{C}$ for the sunny cells. In order to create a partial shadowing condition, one cell in the cell string is covered with a sheet of cardboard, which makes the shadowing close to $100 \%$, i.e., near zero solar irradiation on the covered area.

Three shading schemes for testing the characteristic output of the PV array under partial shading conditions were conducted (Table 2). Figures 7, 8 and 9 show the I-V characteristic curves of the tested PV array under three partial shading schemes. It is clear that under the shading conditions the I-V curves have multiple local maxima.

Figure 7 shows the I-V curve under the partial shading conditions of the testing scheme 1 , at which only the 3 cell strings in the PV module 2 are partially shaded. The state of the three bypass diodes protecting the cell strings of module 2 are all in the non-conducting state.

The aim of the partial shading conditions of the testing scheme 2 is to test the I-V curve when one bypass diode is affected by the shaded cell string in the PV module 1 . As shown in Fig. 8, the I-V curve is deformed. For voltage values higher than $2 / 3 \mathrm{Vco}$, the total current decreases by $50 \%$ because the PV array behaves as a single PV module.

Figure 9 shows that for the I-V characteristic, simulated with Matlab, the current is almost zero. Also, the operating points of the I-V characteristic obtained experimentally, have a low value of current because of the conducting states of all the diodes bypass. It is to be noted that the current scale used for Fig. $8(1 \mathrm{~A} /$ div $)$ is ten times higher than the one used for Fig. $9(0.1 \mathrm{~A} / \mathrm{div})$. This underlines the quite absence of output current both with simulation and under experimental tests.

Figures 7,8 and 9 show the simulated and experimental I-V curve of the PV array partially shaded. Consequently, the high consistency between simulated and experimental $\mathrm{I}-\mathrm{V}$ curves can be proved.

\section{Result analysis and discussion}

The comparison between the experimental results and those simulated using the proposed modeling method confirm two aspects.

First, the calculation of the five parameters use simpler equations than presented in [16]. This is due to the fact to considering the value of the series Resistance Rs 
Table 2 Partial shading conditions and environmental data

\begin{tabular}{lll}
\hline Testing scheme & Shading condition of module 1 & Shading condition of module 2 \\
\hline 1 & No shading & Cell strings (2_1), (2_2), (2_3) \\
2 & Cell string (1_1) & No shading \\
3 & Cell strings (1_1),(1_2),(1_3) & Cell strings (2_1), (2_2), (2_3) \\
\hline
\end{tabular}

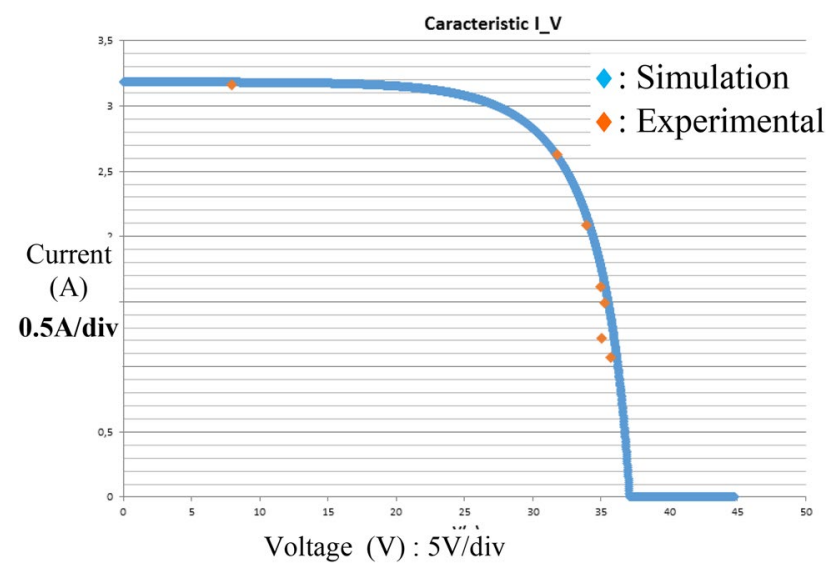

Fig. 7 I-V curve under the shading condition of testing scheme 1

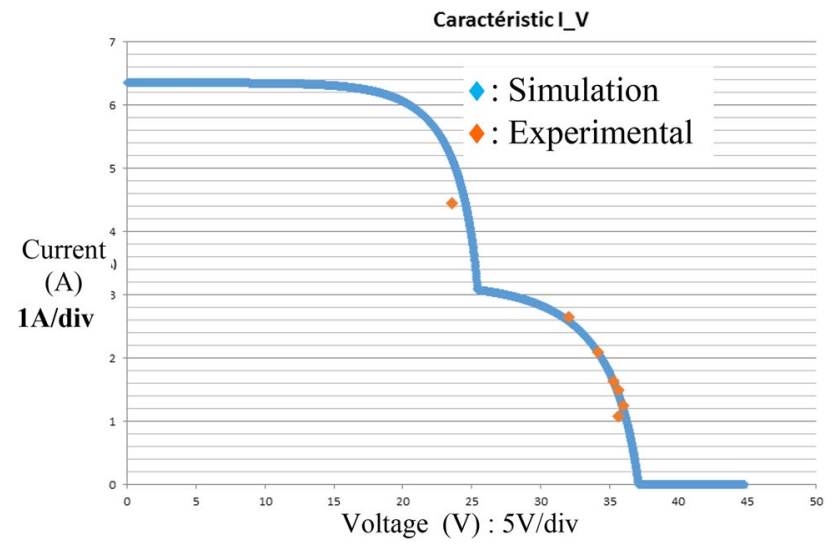

Fig. 8 I-V curve under the shading condition of testing scheme 2

sufficiently small and the simplification of the two terms $(\mathrm{dV} / \mathrm{dl})_{\mathrm{V}=0}$ and $(\mathrm{dV} / \mathrm{dl})_{\mid=0}$ as detailed in [20].

In addition, we presented in this paper a modeling of a PV array under partial shading conditions, and the array can be a series and/or parallel configuration of PV modules. Indeed, the model provided by [16], which is available only for series configuration, is extended by the means of simple considering simply the same voltage segmentation as for the cell configuration. The obtained experimental results confirm the performances of the proposed model.

The proposed model is suitable for intermediate irradiation values and is not limited to $0 \%$ or $100 \%$ ones. This is of great interest because major real applications represent

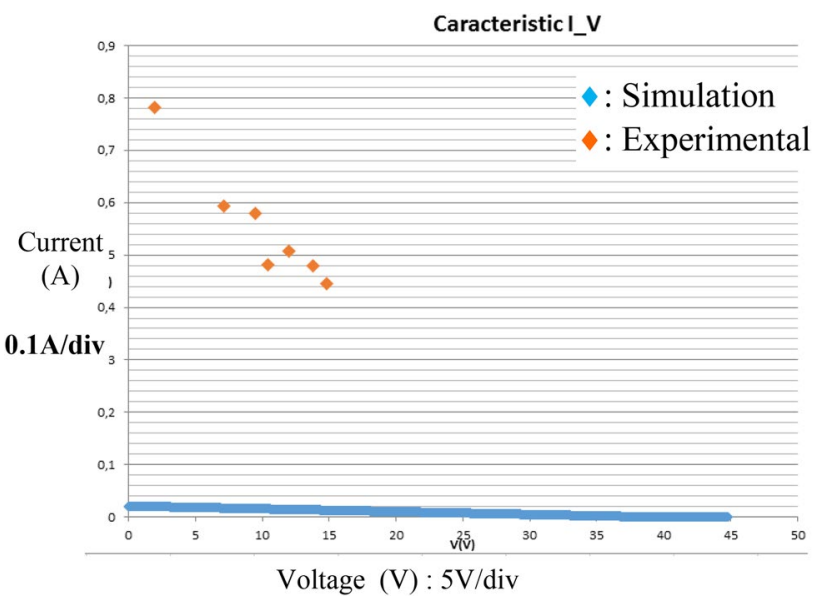

Fig. 9 I-V curve under the shading condition of testing scheme 3

this second case. Consequently, our next experimental tests will include such scenarios. Furthermore, the proposed model will be used in the control part of PV emulator systems. Such a system consists mainly in a power converter controlled in order to have its output voltage and current matching the I-V curve of the emulated PV installations. The second important application of a such a modeling for partial shaded PV systems is the monitoring of large PV installations in order to detect possible failures caused by soiling, dust deposit or any obstacle on the active area such as leaves, neighboring buildings or trees.

\section{Conclusion}

The determination of the I-V characteristic of a partially shaded PV array is an interesting challenge since such an accurate curve models the PV panel output behavior under real and variable climate and environment conditions. As mentioned in the paragraph $\mathrm{V}$ this model can be used for the PV emulator design or for PV plants monitoring and fault detection. The simple one-diode model of one PV panel is used to describe the PV plant behavior when the Temperature and irradiance is uniform on the plant surface. This model involve five parameters that can be easily calculated under such conditions.

This paper considered the case when one PV plant receives non-uniform irradiance, i.e. under partial shading condition and proposed a methodology to calculate 
the five parameters of the one-diode model using only the available data provided by the manufacturer. Indeed, the paper pointed out a simple method to mathematically determine the expression of these five parameters. Then, the development of the procedure to determine the I-V characteristic of PV array composed of several series or parallel modules is presented taking into account the weather and partial shading conditions.

To verify the accuracy of the proposed method of determining the characteristic I-V for a PV array under partial shading conditions, three testing schemes with different shading conditions in the PV array were carried out. The experimental results has proven that the proposed method has great accuracy in simulating the I-V characteristic of a PV array under partial shading conditions. The ultimate goal of this paper is to provide the reader with essential information to easily develop the model of photovoltaic array under partial shading conditions and to predict the output of a real PV array under complex operating conditions. It can be efficiently used for example to design accurate photovoltaic generator emulators that meet the EN 50530 European standard requirements. Also, the proposed model of partially shaded PV installations could be used to create various PV plant I-V curves for different partial shading conditions. These I-V curves could be form a database and the comparison of an measured IV curve and those of the database could be used to determine the partial shadow condition and detect possible failures caused by soiling or the existence of an obstacle on the PV cells such as leaves or neighboring buildings.

Acknowledgements The author would like to thank Miss Khaoula Khaskhoussy and Mr Nouri Makhlouf from CETIME (Mechanical and Electrical Industries Technical Centre) for the support they provide especially to conduct the experimental tests.

Funding This work was supported by the Tunisian Ministry of High Education and Research under Grant LSE-ENIT-LR 11ES15 and funded in part by NAS and USAID under the USAID Prime Award Number AID-OAA-A-11-00012. This Award ig given for the PEER (Partnerships For Enhanced Engagement In Research) Project, named 'Impact of rooftop PV system integration on Tunisian electrical distribution network' [10]. Any opinions, findings, conclusions, or recommendations expressed in this article are those of the authors alone, and do not necessarily reflect the views of USAID or NAS.

\section{Compliance with ethical standards}

Conflict of interest The authors declare that they have no conflict of interest.

\section{References}

1. Hamdan I, Maghraby A, Noureldeen O (2019) Stability improvement and control of grid-connected photovoltaic system during faults using supercapacitor. SN Appl Sci 1:1687

2. Wittmer B, Mermoud A, Schott T (2015) Analysis of Pv grid installations performance, comparing measured data to simulation results to identify problems in operation and monitoring. In: 30th European photovoltaic solar energy conference and exhibition, Hamburg, Germany, 14-18 Sept 2015

3. Triki-Lahiani A, Abdelghani AB, Slama-Belkhodja I (2018) Fault detection and monitoring systems for photovoltaic installations: a review. Renew Sustain Energy Rev 82(P3):2680-2692

4. Galan DM, Starzak L, Torzewicz T, Piotrowicz M, Marańda W (2013) Laboratory setup for investigation of MPPT algorithms of photovoltaic modules under non-uniform insolation. In: Proceedings of the 20th international conference mixed design of integrated circuits and systems, MIXDES; Gdynia, Poland, 20-22 June 2013

5. Kordestani M, Mirzaee A, Safavi AA, Saif M (2018) Maximum power point tracker (MPPT) for photovoltaic power systems-a systematic literature review. In: 2018 European control conference (ECC), Limassol, Cyprus, 12-15 June 2018

6. Benkercha R, Moulahoum S, Colak I (2017) Modelling of fuzzy logic controller of a maximum power point tracker based on artificial neural network. In: 16th IEEE international conference on machine learning and applications (ICMLA), 18-21 Dec 2017, Cancun, Mexico

7. Rajabi M, Hosseini SH (2019) Maximum power point tracking in photovoltaic systems under different operational conditions by using ZA-INC algorithm. SN Appl Sci 1:1535

8. Shazly SA, El Sattar MA (2019) A comparative study of P\&O and INC maximum power point tracking techniques for grid-connected PV systems. SN Appl Sci 1:174

9. Al-Baik D, Khadkikar V (2011) Effect of variable PV power on the grid power factor under different load conditions. In: 2nd International conference on electric power and energy conversion systems (EPECS), Sharjah, United Arab Emirates

10. Refaat SS, Abu-Rub H, Sanfilippo AP, Mohamed A (2018) Impact of grid-tied large-scale photovoltaic system on dynamic voltage stability of electric power grids. IET Renew Power Gener 12(2):157-164

11. Mukwekwe L, Venugopal C, Davidson IE (2017) A review of the impacts and mitigation strategies of high PV penetration in low voltage networks. IEEE PES PowerAfrica, Accra, Ghana, 27-30 June 2017

12. https://sites.nationalacademies.org/PGA/PEER/PEERscience/ PGA_189097

13. Ji YH, Kim JG, Park SH, Kim JH, Won CY (2009) C-language based $\mathrm{PV}$ array simulation technique considering effects of partial shading. In: IEEE international conference on industrial technology, 10-13 Feb 2009, Gippsland, VIC, Australia

14. Notton G, Caluianu I, ColdaCaluianu S (2010) Influence of partial shading on the electrical production of a photovoltaic module of monocrystalline silicon. J Renew Energ 13(1):49-62

15. Ye B, Qi J, Li Y, Xie L, Yang F (2017) Research on PV array output characteristics based on shadow image recognition. In: IEEE conference on energy internet and energy system integration (EI2), 26-28 Nov 2017, Beijing, China

16. Bai J, Cao Y, Hao Y, Zhang Z, Cao F (2015) Characteristic output of PV systems under partial shading or mismatch conditions. Sol Energy 112:41-54

17. Sera D, Baghzouz Y (2008) MATLAB based modelling and performance study of series connected SPVA under partial shaded conditions. In: 2nd WSEAS/IASME international conference on 
Renewable Energy Sources (RES'08) Corfu, Greece, October 26-28

18. Ji YH, Kim JG, Park SH, Kim JH, Won CY (2009) C-language based PV array simulation technique considering effects of partial shading. In: 2009 IEEE international conference on industrial technology, 10-13 Feb. 2009, Gippsland, Australia

19. Townsend TU (1989) A method for estimating the log-term performance of direct-coupled photovoltaic systems. University of Winconsin

20. Padmanabhan B (2009) Contribution to the modeling of a solar cell. Degree master of science thesis, Arizona State University
21. De Soto W (2006) Improvement and validation of a model for photovoltaic array performance. Sol Energy 80(1):78-88

22. Souza LR, Cortizo CP, Mendes ASM (2013) Study and design of a photovoltaic array simulator. In: 2013 Brazilian power electronics conference, 27-31 Oct 2013, Gramado, Brazil

Publisher's Note Springer Nature remains neutral with regard to jurisdictional claims in published maps and institutional affiliations. 